\title{
Increasing the production
} of $(R)$-3-hydroxybutyrate in recombinant Escherichia coli by improved cofactor supply

\author{
Mariel Perez-Zabaleta1,2, Gustav Sjöberg ', Mónica Guevara-Martínez ${ }^{1,2}$, Johan Jarmander , Martin Gustavsson',
} Jorge Quillaguamán ${ }^{2}$ and Gen Larsson ${ }^{1 *}$

\begin{abstract}
Background: In a recently discovered microorganism, Halomonas boliviensis, polyhydroxybutyrate production was extensive and in contrast to other PHB producers, contained a set of alleles for the enzymes of this pathway. Also the monomer, $(R)$-3-hydroxybutyrate (3HB), possesses features that are interesting for commercial production, in particular the synthesis of fine chemicals with chiral specificity. Production with a halophilic organism is however not without serious drawbacks, wherefore it was desirable to introduce the $3 \mathrm{HB}$ pathway into Escherichia coli.
\end{abstract}

Results: The production of $3 \mathrm{HB}$ is a two-step process where the acetoacetyl-CoA reductase was shown to accept both NADH and NADPH, but where the $V_{\max }$ for the latter was eight times higher. It was hypothesized that NADPH could be limiting production due to less abundance than $\mathrm{NADH}$, and two strategies were employed to increase the availability; (1) glutamate was chosen as nitrogen source to minimize the NADPH consumption associated with ammonium salts and (2) glucose-6-phosphate dehydrogenase was overexpressed to improve NADPH production from the pentose phosphate pathway. Supplementation of glutamate during batch cultivation gave the highest specific productivity $\left(\mathrm{q}_{3 \mathrm{HB}}=0.12 \mathrm{~g} \mathrm{~g}^{-1} \mathrm{~h}^{-1}\right)$, while nitrogen depletion/zwf overexpression gave the highest yield $\left(\mathrm{Y}_{3 \mathrm{HB} / \mathrm{CDW}}=0.53 \mathrm{~g} \mathrm{~g}^{-1}\right)$ and a $3 \mathrm{HB}$ concentration of $1 \mathrm{~g} \mathrm{~L}^{-1}$, which was $50 \%$ higher than the reference. A nitrogenlimited fedbatch process gave a concentration of $12.7 \mathrm{~g} \mathrm{~L}^{-1}$ and a productivity of $0.42 \mathrm{~g} \mathrm{~L}^{-1} \mathrm{~h}^{-1}$, which is comparable to maximum values found in recombinant $E$. coli.

Conclusions: Increased NADPH supply is a valuable tool to increase recombinant $3 \mathrm{HB}$ production in E. coli, and the inherent hydrolysis of CoA leads to a natural export of the product to the medium. Acetic acid production is still the dominating by-product and this needs attention in the future to increase the volumetric productivity further.

Keywords: Escherichia coli, Halomonas boliviensis, (R)-3-hydroxybutyrate, Acetoacetyl-CoA reductase, NADPH, zwf overexpression, Glutamate, Nitrogen limitation

\section{Background}

Microorganisms are increasingly used for production of renewable chemicals and biomaterials [1]. One example is the polymer polyhydroxybutyrate (PHB), but also other commercially interesting polyhydroxyalkanoates have been investigated for use as bioplastics [2]. The monomer

\footnotetext{
*Correspondence: gen@kth.se

${ }^{1}$ Division of Industrial Biotechnology, School of Biotechnology, KTH Royal Institute of Technology, AlbaNova University Center, SE 10691 Stockholm, Sweden

Full list of author information is available at the end of the article
}

of $\mathrm{PHB},(R)$-3-hydroxybutyrate (3HB), has potential applications apart from polyester production, e.g. as an intermediate in the synthesis of antibiotics, vitamins, aromatic derivatives and pheromones [3-6]. Several of these applications require a specific enantiomer of $3 \mathrm{HB}$, which makes microbial production highly interesting due to the stereospecificity of the involved enzymes.

Halomonas boliviensis is a halophilic bacterium that is known to accumulate PHB to over $80 \%$ of its cell dry weight (CDW) and to achieve volumetric productivities of up to $1.1 \mathrm{~g} \mathrm{~L}^{-1} \mathrm{~h}^{-1}$ [7]. The genome of this 
microorganism has experienced significant horizontal gene transfer and has thus obtained a wide range of genes for carbohydrate metabolism, as well as for PHB production [8]. For the production of PHB three enzymes are needed and $H$. boliviensis possesses seven alleles of the $\beta$-ketothiolase, one allele of the acetoacetyl-CoA reductase and three alleles of the PHB synthase. These alleles are however scattered over the chromosome and are not organized into operons, as in e.g. Cupriavidus necator [9]. Due to the efficient production of PHB in H. boliviensis, this organism is an interesting source of enzymes for recombinant production of PHB as well as $3 \mathrm{HB}$. The engineering of $H$. boliviensis is however considerably more difficult than common commercial organisms due to the lack of genetic tools and metabolic data. In addition, cultivation of Halomonas strains is associated with a need for high salt concentrations, making it unsuitable for use in commercial stainless steel bioreactors due to corrosive damage. We have thus chosen to express the genes for 3HB production from $\mathrm{H}$. boliviensis in Escherichia coli, an organism that does not naturally produce PHB. From earlier experiments it was seen that E. coli most likely expresses the enzyme thioesterase II (tesB), which is capable of hydrolysis of $(R)$-3-hydroxybutyrateCoA (3HB-CoA), which in turn leads to excretion of $3 \mathrm{HB}$ to the medium [10]. This is an added benefit with expression in $E$. coli since its results in a primary purification of the product.

The synthesis of $3 \mathrm{HB}$ is a two-step reaction. The enzyme $\beta$-ketothiolase first catalyzes the condensation of two molecules of acetyl-CoA to acetoacetyl-CoA where after the acetoacetyl-CoA reductase further catalyzes the formation of 3HB-CoA (Fig. 1). From the seven alleles of $\beta$-ketothiolase found in $H$. boliviensis the $t 3$ gene was initially selected due to its suggested sequence similarity with the thiolase of $C$. necator. Only one allele for the reductase was found in Halomonas boliviensis ( $r x$ ), which was chosen but where the cofactor was unknown due to the recent discovery of the organism. Many acetoacetylCoA reductases involved in $\mathrm{PHB}$ formation are known to be NADPH-dependent but the acetoacetyl-CoA reductase obtained from Allochromatium vinosum is one exception [2] and the specific cofactor-dependence can thus not be presumed.

\section{Results and discussion}

\section{Cofactor specificity of the $\mathrm{H}$. boliviensis acetoacetyl-CoA reductase}

In order to determine the cofactor specificity of the reductase, the enzyme was produced in $E$. coli and purified using metal ion chromatography. The kinetic parameters of the reductase were subsequently analyzed using either NADH or NADPH as cofactors with

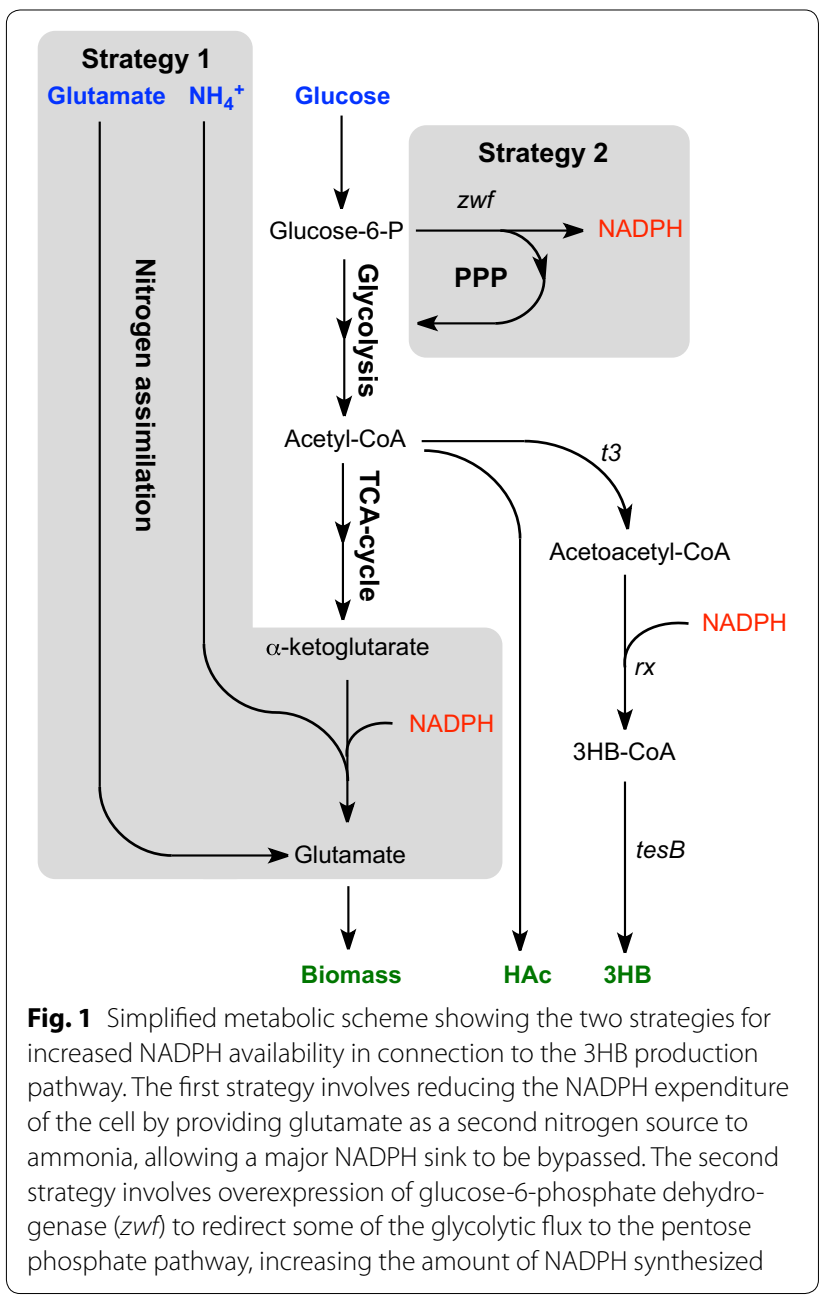

acetoacetyl-CoA as substrate (Fig. 2). The values of the maximum rates $\left(V_{\max }\right)$ were $1.6 \mu \mathrm{M} \mathrm{mg} \mathrm{min}^{-1}$

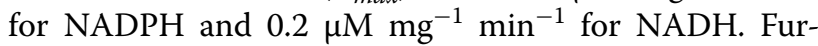
thermore, the saturation constants $\left(K_{M}\right)$ were 70 and $24 \mu \mathrm{M}$, for NADPH and NADH, respectively (Table 1 ). From Fig. 2 and Table 1 it is evident that increasing the $\mathrm{NADPH}$ availability could potentially have a big impact on the conversion rate of acetoacetyl-CoA to 3HB-CoA, since the $V_{\text {max }}$ for NADPH is eight times higher than for $\mathrm{NADH}$. These results suggest that $3 \mathrm{HB}-\mathrm{CoA}$ synthesis is adaptable to different conditions in $\mathrm{H}$. boliviensis, i.e. that a basal production rate can be maintained using NADH also when NADPH concentrations are low, while it can be greatly increased whenever an excess of NADPH is available.

A phylogenetic study was conducted, comparing the Halomonas reductase gene $(r x)$ to other reductase genes with known cofactor specificity. Figure 3 shows that $r x$ is most closely related to reductases from other Halomonas species and a group containing the reductase from 


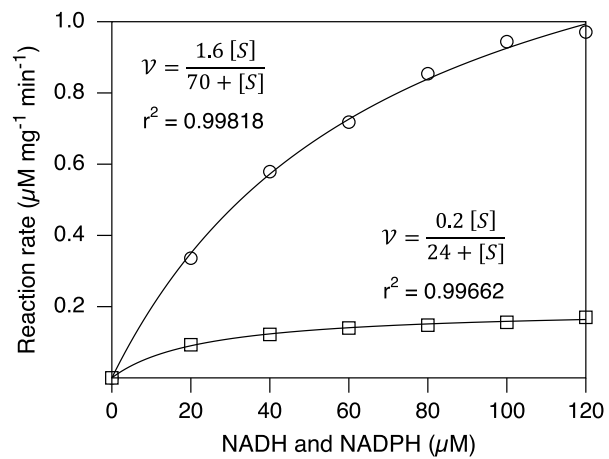

Fig. 2 Kinetic model of His-tagged acetoacetyl-CoA reductase synthesized by gene $r x$ that was obtained from-the $\mathrm{H}$. boliviensis. Symbols refer to NADH (squares) and NADPH (circles). The reaction rates at different concentrations of $\mathrm{NADH}$ and $\mathrm{NADPH}$, respectively, were curve fitted to the Michaelis-Menten equation to obtain the values of $V_{\max }$ and $K_{M}$ for each cofactor

Table 1 Kinetic parameters of the acetoacetyl-CoA reductase from $H$. boliviensis

\begin{tabular}{|c|c|c|c|c|}
\hline Cofactor & $\begin{array}{l}\mathrm{V}_{\max } \\
\left(\mu \mathrm{mol} \mathrm{mg}^{-1} \mathrm{~min}^{-1}\right)\end{array}$ & $\mathrm{K}_{\mathrm{M}}(\mu \mathrm{M})$ & $\mathrm{k}_{\text {cat }}\left(\mathrm{s}^{-1}\right)$ & $\begin{array}{l}k_{\text {cat }} / K_{M} \\
\left(s^{-1} \mu M^{-1}\right)\end{array}$ \\
\hline NADPH & $1.6 \pm 0.2$ & $70 \pm 6$ & $780 \pm 100$ & $11.1 \pm 0.3$ \\
\hline $\mathrm{NADH}$ & $0.20 \pm 0.02$ & $24 \pm 6$ & $100 \pm 7$ & $4.2 \pm 0.2$ \\
\hline
\end{tabular}

Zoogloea ramigera, which has been found to be NADPH dependent [11]. In a more distant branch, a third cluster is formed that contain a reductase from $A$. vinosum which is known to be NADH dependent [12]. The wellknown NADPH dependent reductase in the $p h b C A B$ operon [9] from of Cupriavidus necator (previously known as Ralstonia eutropha and Alcaligenes eutrophus), is however one of the most distantly related reductases. From the phylogenetic tree (Fig. 3), it could be concluded that $r x$ exhibited similarity to both NADPH and NADH dependent reductase genes. Taken together, it can be concluded that the $H$. boliviensis reductase $(r x)$ accepts both $\mathrm{NADPH}$ and $\mathrm{NADH}$ as the reducing agent while there is a clear preference towards NADPH.

\section{Increasing NADPH availability}

A critical step in recombinant production from inserts of whole new synthesis pathways is the supply and generation of cofactors which points to the acetoacetylCoA reductase catalyzed step as crucial. The availability of NADPH is restricted and we thus hypothesized that increased availability might improve the $3 \mathrm{HB}$ production. The first attempt to improve the cofactor availability was to reduce the amount of NADPH consumed by the cell which was done by shifting the nitrogen source from ammonium salt to glutamate (Fig. 1). This would bypass the first step in ammonia assimilation, where the cell spends one equivalent of NADPH when glutamate is produced from ammonia and $\alpha$-ketoglutarate, leaving it available for 3HB-CoA production. We found however that the uptake of glutamate in $E$. coli is very slow, resulting in almost no growth if utilized as the only nitrogen source. A medium containing both ammonium and glutamate was therefore used. In the second attempt, the gene $z w f$, which encodes for the enzyme glucose-6-phosphate dehydrogenase catalyzing the first committed step in the pentose phosphate pathway (PPP), was overproduced (Fig. 1). This reaction sequence is the major cellular source of NADPH formation and $z w f$ overexpression was previously described to improve cofactor balance however in PHB production [13].

Both NADPH-increasing strategies were first evaluated in bioreactors during batch conditions with unrestricted cell growth and at glucose excess. This leads to allosteric inhibition of citrate synthase by $\mathrm{NADH}$, a reduced TCA activity and the formation of acetic acid due to the glycolytic overflow [14]. It was speculated that the introduction of the $3 \mathrm{HB}$ pathway would lead to a redirection of the carbon flux from acetic acid to this product. As shown in the first part of Table 2, the strain with access to glutamate produced $3 \mathrm{HB}$ at the highest specific rate i.e. $\mathrm{q}_{3 \mathrm{HB}}=0.12 \mathrm{~g} \mathrm{~g}^{-1} \mathrm{~h}^{-1}$, while the strain overexpressing $z w f$ gave the highest concentration i.e. $0.73 \mathrm{~g} \mathrm{~L}^{-1}$. Both strategies resulted in higher $3 \mathrm{HB}$ concentrations, higher yields and both improved specific and volumetric production rates as compared to the reference. It was further noted that the strain carrying the production plasmids as well as the additional plasmid for $z w f$ overexpression did not suffer from the increased metabolic load and the specific growth rate remained high.

\section{Cultivations using nitrogen depletion for improved $3 \mathrm{HB}$ production}

Since both strategies for improving the intracellular NADPH levels were promising, we hypothesized that the productivities, yields and titers from the batch cultivations could be further improved by depletion of nitrogen while glucose remained in excess. This is a well-known cellular strategy in wild type polyhydroxyalkanoate (PHA) producers where a specific limitation e.g. in nitrogen, controls the growth rate while the NADH overflow from a high glycolytic flux leads to TCA cycle restriction, thus promoting a redistribution of the carbon flux from cell growth to the PHA production.

The cultivations were performed in two phases: (1) a batch phase with all nutrients in excess followed by phase (2) i.e. nitrogen depletion but with all other nutrients present in excess. As shown in Fig. 4, the cell mass in phase 2 slightly increases in a linear fashion despite the lack of the 




Fig. 3 Phylogenetic tree of Halomonas boliviensis related acetoacetyl-CoA reductases. Phylogenetic relationship among enzymes was found by maximum-likelihood (ML) tree-building strategy. GenBank accession numbers are given in parenthesis

major nitrogen substrate component, which is different from the case when glucose is depleted and the cell immediately enters into a stationary phase. In the figure is also seen that in spite of the ammonium depletion $3 \mathrm{HB}$ production continues while cell growth is radically reduced which confirms the presence of the metabolic regulation targeted above. In Fig. 4 is seen that the highest specific production rate of $3 \mathrm{HB}$ was observed with overexpression of $z w f\left(\mathrm{q}_{3 \mathrm{HB}}=0.06 \mathrm{~g} \mathrm{~g}^{-1} \mathrm{~h}^{-1}\right)$ and this led to a $50 \%$ higher 3HB titer $\left(1 \mathrm{~g} \mathrm{~L}^{-1}\right)$ than in the reference cultivation. The reduced cell growth during the depletion phase results also in a substantially increase of the yield, $\mathrm{Y}_{3 \mathrm{HB} / \mathrm{CDW}}$ and in the highest value achieved i.e. $0.53 \mathrm{~g} \mathrm{~g}^{-1}$ (Table 2). Since $3 \mathrm{HB}$ production kinetics follows a mixed growth pattern with production both during growth and depletion, nitrogen starvation can be an interesting strategy to pursue but to increase the productivity, the starvation should be preceded by a phase with maximized cell mass accumulation.

$3 \mathrm{HB}$ is not the only product in the cultivations since acetic acid (HAc) is at all times formed and this route should obviously be avoided since it draws resources from the $3 \mathrm{HB}$ formation. Comparing the HAc production for the cultivations in Fig. 4, it is evident that both $z w f$ overexpression and the use of a glutamate-supplemented medium led to increased HAc production. In the case of $z w f$ overexpression, the specific production rate of HAc $\left(\mathrm{q}_{\mathrm{HAC}}\right)$ correlates well with the specific production rate $\left(\mathrm{q}_{3 \mathrm{HB}}\right)$, which is in line with previous ammonium-depleted cultivations [15]. However, in the case of glutamate excess, HAc production seems not directly coupled to $3 \mathrm{HB}$ production and here we also find the highest HAc production.

Several factors might lead to restrictions in the $3 \mathrm{HB}$ production whereof one is a restricted hydrolysis of coenzyme A (CoA) and a reduced export of $3 \mathrm{HB}$ to the medium. Overexpression of thioesterase II (tesB) has been one method to overcome this supposed bottleneck and was previously used to increase $3 \mathrm{HB}$ production during recombinant $3 \mathrm{HB}$ production in $E$. coli but using the genes of $C$. necator [10]. However, tes $B$ overexpression in our strain did not improve the $3 \mathrm{HB}$ production and resulted in impaired cell growth (Additional file 1: Table S1).

\section{Maximizing the 3HB overproduction by fedbatch cultivation}

The strategy of $z w f$ overexpression seemed to be a suitable means to increase $3 \mathrm{HB}$ production in favour of the glutamate feed strategy, which increased the undesired 


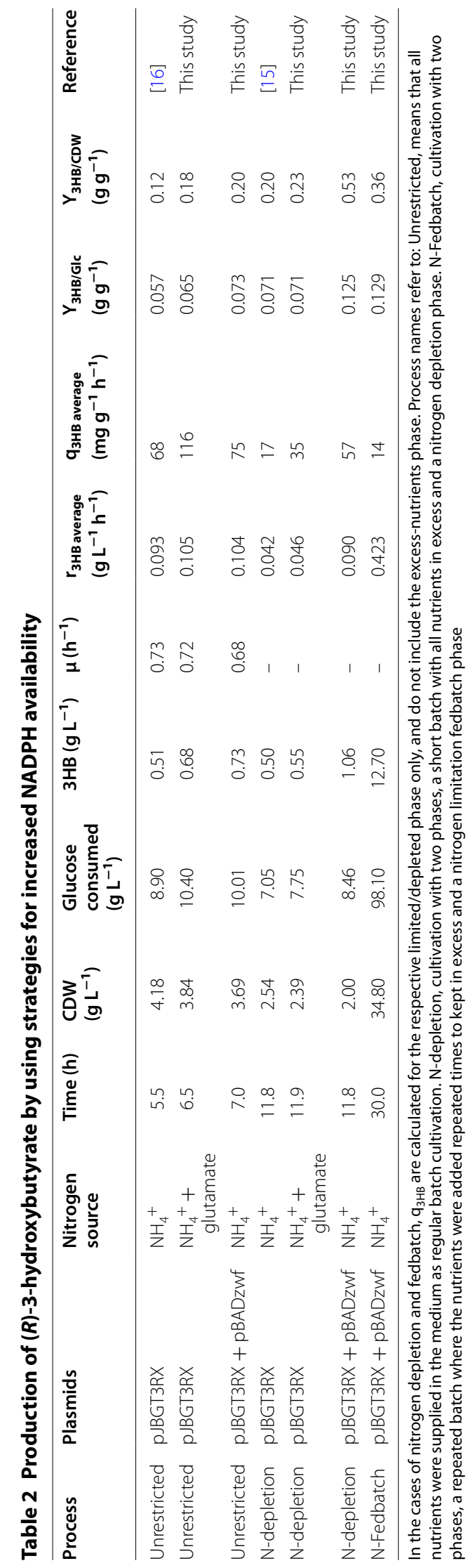




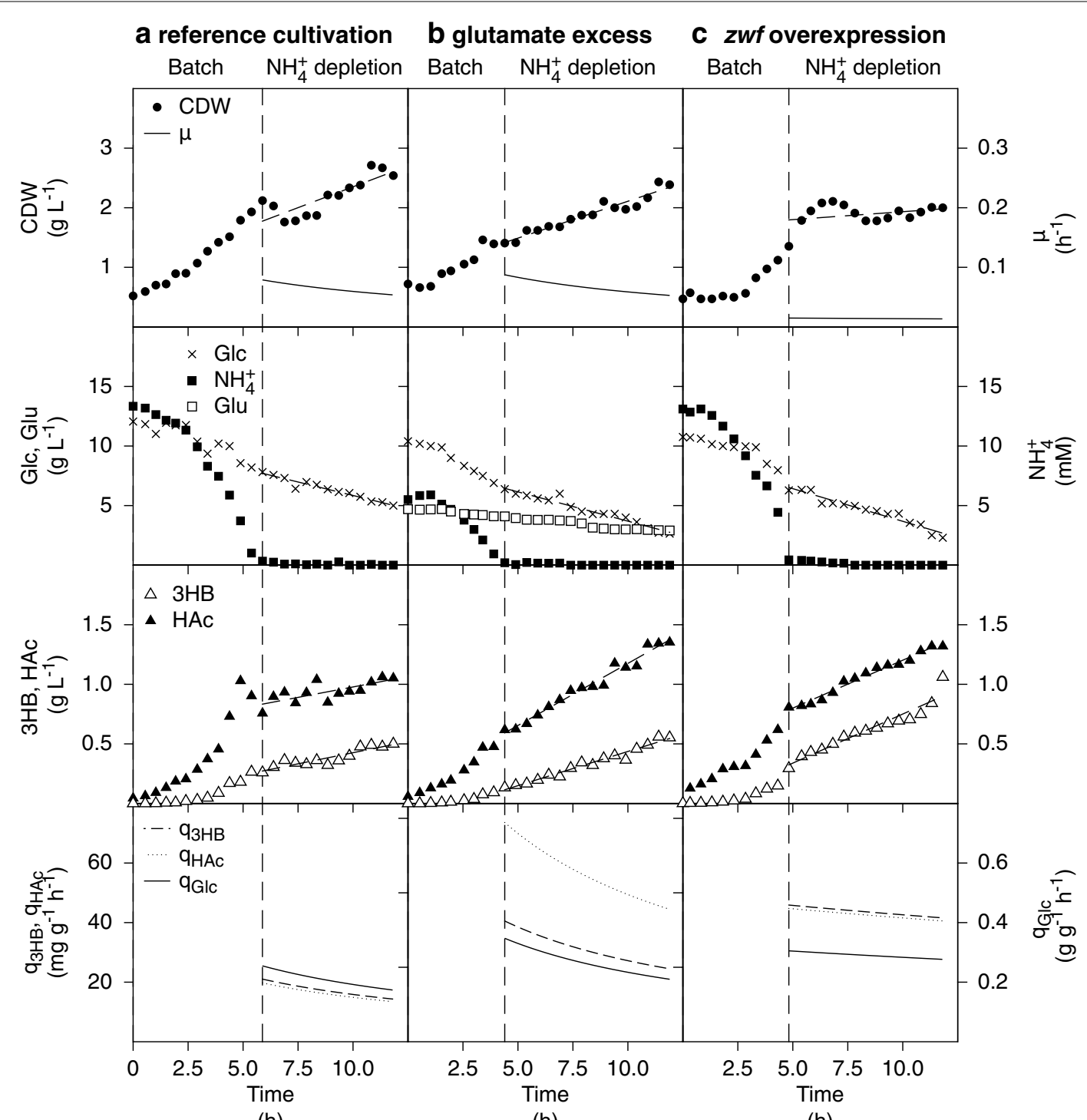

(h)

(h)

(h)

Fig. 4 Production of (R)-3-hydroxybutyrate in E. coli AF1000 a pJBGT3RX, reference cultivation. b pJBGT3RX with excess of glutamate in the medium c pJBGT3RX pBADzwf, in batch mode during ammonium depletion. Symbols refer to cell dry weigh (CDW, filled circles), glucose (Glc, crosses), glutamate (Glu, open squares), ammonium $\left(\mathrm{NH}_{4}{ }^{+}\right.$, closed squares), $3 \mathrm{HB}$ (open triangles) and acetic acid (HAc, closed triangles). The specific productivity of $3 \mathrm{HB}$ has been curve fitted to a 1st order polynomial. The dashed line marks the shift between batch cultivation and nitrogen depletion

formation of acetic acid (Fig. 4). Nitrogen-limited fedbatch cultivation was thus designed to obtain a higher volumetric productivity than possible in simple batch cultivations. The principle outline was a two-phase process where the first phase was designed for accumulation of cell mass under high glucose concentration followed by a fedbatch phase with nitrogen limitation but a continued high feed of glucose. The cultivation in phase 1 was started with repeated batches to avoid the osmotic effects and inhibitions of growth due to the high nutrient concentrations resulting from a single addition. Glucose and $\left(\mathrm{NH}_{4}\right)_{2} \mathrm{SO}_{4}$ was thus added repeatedly giving a final cell density of $22 \mathrm{~g} \mathrm{~L}^{-1}$ (Fig. 5) without oxygen limitation. At $15 \mathrm{~h}$, nitrogen was exhausted and a constant feed phase started where both glucose and $\left(\mathrm{NH}_{4}\right)_{2} \mathrm{SO}_{4}$ was added. The glucose was kept in excess, i.e. above $10 \mathrm{~g} \mathrm{~L}^{-1}$ while the nitrogen was added to limit growth. During the first $10 \mathrm{~h}$ of the experiment, the cells grew with a high specific growth rate $(\mu)$, which was subsequently reduced (Fig. 5) and this was attributed to toxic effects of the accumulation of acetic acid. 


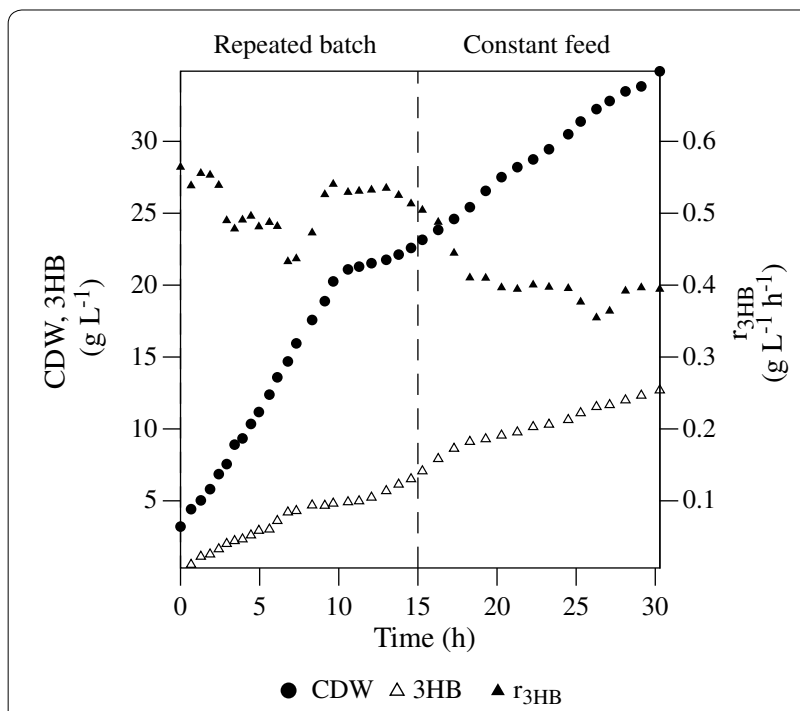

Fig. 5 Production of (R)-3-hydroxybutyrate by E. coli AF1000 pJBGT3RX pBADzwf. Symbols refer to cell dry weigh (CDW, filled circles), $3 \mathrm{HB}$ (open triangles) and volumetric $3 \mathrm{HB}$ production rate $\left(\mathrm{r}_{3 \mathrm{HB}}\right.$, closed triangles). The dashed line marks the shift between repeated batch and the fedbatch phase, respectively

The highest volumetric productivity of $3 \mathrm{HB}$ was observed in the repeated batch phase with a maximum value of $0.56 \mathrm{~g} \mathrm{~L}^{-1} \mathrm{~h}^{-1}$ (Fig. 5) but with an overall productivity of $0.42 \mathrm{~g} \mathrm{~L}^{-1} \mathrm{~h}^{-1}$ (Table 2). The final concentration was $12.7 \mathrm{~g} \mathrm{~L}^{-1}$ that was achieved after $30 \mathrm{~h}$ of cultivation. This value is higher than in previously published work on $3 \mathrm{HB}$ production by recombinant $E$. coli [15-17]. Using genes from $H$. boliviensis, Guevara et al. [15] and Jarmander et al. [16] obtained $4.1 \mathrm{~g} \mathrm{~L}^{-1}$ after $13 \mathrm{~h}$ and $1.9 \mathrm{~g} \mathrm{~L}^{-1}$ after $11 \mathrm{~h}$ of cultivation, respectively. Gao et al. [17] used genes from $C$. necator and achieved to a concentration of $12 \mathrm{~g} \mathrm{~L}^{-1} 3 \mathrm{HB}$ after $48 \mathrm{~h}$ of cultivation under a repetitive batch mode. Furthermore, the concentration and productivity of $3 \mathrm{HB}$ in this study are comparable to the work of Liu et al. where genes from $C$. necator were overexpressed as well as the tes $B$ gene which was here necessary for increased extracellular production [10].

\section{Conclusions}

Several factors influence the production of metabolites from transplantation of new pathways into microorganisms and one central point is the balancing of cofactors. The preferred cofactor of the reductase gene transplanted from Halomonas boliviensis was shown to be NADPH to which the access is limited in the cell in comparison to NADH. We thus hypothesized that this could constitute a bottleneck in $3 \mathrm{HB}$ production and increasing the supply would allow a higher production. This hypothesis was verified since the proposed strategies both lead to increased product formation and where the $z w f$ overexpression strategy gave $50 \%$ better results than the reference. The attempt to reduce NADPH consumption was not as successful due to the low assimilation rate of glutamate in E. coli. The high $3 \mathrm{HB}$ titer of $12.7 \mathrm{~g} \mathrm{~L}^{-1}$ and the volumetric productivity of $0.42 \mathrm{~g} \mathrm{~L}^{-1} \mathrm{~h}^{-1}$ during $z w f$ overexpression are comparable to maximum values found in the literature with $E$. coli however based on genes from C. necator [10].

The productivity in E. coli so far is however only $30 \%$ of the values in $H$. boliviensis and a main factor is the accumulation of acetic acid, which is still present in spite of the use of the wild type PHB strategy with glucose excess and nitrogen limitation to force the carbon flux to 3HB. This is undesired since it lowers the growth rate and captures the carbon aimed for the product. This points however also to the important fact that the $3 \mathrm{HB}$ precursor acetyl-CoA is present in abundance.

\section{Methods}

\section{Strains and plasmids}

The E. coli strain AF1000 (MC4100, relA1 $\left.{ }^{+}\right)$[18] was used for expression of the genes $r x, r x H_{i s}, t 3$ and $z w f$, as well as for production of $3 \mathrm{HB}$. The E. coli strain DH5 $\alpha$ was used for all cloning procedures. The plasmid pJBGT3RX was used for $3 \mathrm{HB}$ production. It was constructed by SLIC insertion of $r x$ and $t 3$ to pKM1D, a pACYC184-derived low copy number plasmid with ori $\mathrm{p} 15 \mathrm{~A}$, a lacUV5 promoter, a multiple cloning site, the lacIq repressor and a chloramphenicol resistance gene (Additional file 1: Figure S1). The plasmid pBAD $z w f$ for increasing intracellular NADPH concentrations was constructed from pBAD/HisC (Invitrogen), a plasmid with the pBR322 ori, the araBAD promoter and an ampicillin resistance gene. From DH $5 \alpha, z w f$ was amplified by PCR with complementary tails to the NcoI and EcoRI sites of pBAD/HisC. The plasmid was digested with EcoRI and NcoI followed by SLIC assembly $[19,20]$ to $z w f$. The plasmid pTrc99RX$\mathrm{His}_{6}$ for purifying $\mathrm{rxHis}_{6}$ was constructed from pTrc99A [21], a plasmid with pBR322 ori, the lacI repressor, the trc promoter and an ampicillin resistance gene. From pJBGT3RX, the gene $r x$ was amplified by PCR with complementary tails to the NcoI site of pTrc99A. The plasmid was digested with NcoI followed by SLIC assembly [20] to $r x$.

\section{Growth medium and cultivation conditions}

Cultivations were carried out in autoclaved minimal medium containing $7 \mathrm{~g} \mathrm{~L}^{-1}\left(\mathrm{NH}_{4}\right)_{2} \mathrm{SO}_{4}, 1.6 \mathrm{~g} \mathrm{~L}^{-1}$

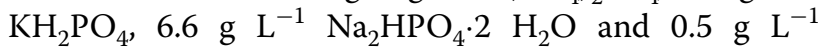
$\left(\mathrm{NH}_{4}\right)_{2}-\mathrm{H}$-(citrate). After sterilization, antibiotics (ampicillin, $100 \mu \mathrm{g} \mathrm{mL}^{-1}$, for pTrc99A and pBAD; and chloramphenicol, $50 \mu \mathrm{g} \mathrm{mL} \mathrm{L}^{-1}$, for $\mathrm{pJBG}$ ), glucose $10 \mathrm{~g} \mathrm{~L}^{-1}$, 
$1 \mathrm{mM} \mathrm{MgSO}_{4}$ and a $1000 \times$ trace elements solution $\left(0.5 \mathrm{~g} \mathrm{~L}^{-1} \mathrm{CaCl}_{2} \cdot 2 \mathrm{H}_{2} \mathrm{O}, 16.7 \mathrm{~g} \mathrm{~L}^{-1} \mathrm{FeCl} 3 \cdot 6 \mathrm{H}_{2} \mathrm{O}, 0.18 \mathrm{~g} \mathrm{~L}^{-1}\right.$ $\mathrm{ZnSO} 4 \cdot 7 \mathrm{H}_{2} \mathrm{O}, 0.16 \mathrm{~g} \mathrm{~L}^{-1} \mathrm{CuSO}_{4} \cdot 5 \mathrm{H}_{2} \mathrm{O}, 0.11 \mathrm{~g} \mathrm{~L}^{-1}$ $\mathrm{MnSO}_{4} \cdot \mathrm{H}_{2} \mathrm{O}, 0.18 \mathrm{gL}^{-1} \mathrm{CoCl}_{2} \cdot 6 \mathrm{H}_{2} \mathrm{O}, 20.1 \mathrm{gL}^{-1} \mathrm{Na}-$ EDTA) were also added to the medium. In batch experiments, $10 \mathrm{~L}$ stirred tank reactor was used with $7 \mathrm{~L}$ of cultivation medium. The cultivation temperature was $37{ }^{\circ} \mathrm{C}$ and the $\mathrm{pH}$ were kept at 7 using $3 \mathrm{M} \mathrm{NH}_{4} \mathrm{OH}$. The cultivations were performed until the glucose was depleted from the medium.

For ammonia depleted experiments, the concentration of $\left(\mathrm{NH}_{4}\right)_{2} \mathrm{SO}_{4}$ was reduced to $1 \mathrm{~g} \mathrm{~L}^{-1}$ and $\left(\mathrm{NH}_{4}\right)_{2}$ $\mathrm{H}$-(citrate) was substituted with $0.65 \mathrm{~g} \mathrm{~L}^{-1} \mathrm{Na}_{3}$-(citrate). Titration was in those cases carried out with $3 \mathrm{M} \mathrm{NaOH}$. In the glutamate supplemented cultivations, glutamate was added to a final concentration of $4.5 \mathrm{~g} \mathrm{~L}^{-1}$.

Fedbatch fermentation was performed in a $15 \mathrm{~L}$ bioreactor containing initially $8 \mathrm{~L}$ of minimal medium. The fermentation process was started with a repeated batch phase followed by a constant feed of glucose and $\left(\mathrm{NH}_{4}\right)_{2} \mathrm{SO}_{4}$, where the latter was the limiting substrate. In the repeated batch phase, glucose was added repeatedly in order to keep the concentration above $10 \mathrm{~g} \mathrm{~L}^{-1}$. The initial concentration of $\left(\mathrm{NH}_{4}\right)_{2} \mathrm{SO}_{4}$ was $7 \mathrm{~g} \mathrm{~L}^{-1}$, when ammonium was depleted, as indicated by an increase in DOT, another $7 \mathrm{~g} \mathrm{~L}^{-1}$ was added to allow high cell density. When the ammonium was depleted for a second time, the constant feed started. The $\mathrm{pH}$ was adjusted using $9 \mathrm{M} \mathrm{NaOH}$ solution.

AF1000 pJBGT3RX or AF1000 pJBGT3RX pBADzwf were inoculated from a glycerol stock stored at $-80{ }^{\circ} \mathrm{C}$ to shake flasks containing $500 \mathrm{ml}$ cultivation medium. The cells were cultivated over night at $37^{\circ} \mathrm{C}$ and $180 \mathrm{rpm}$ and then used to inoculate the bioreactor. Induction was performed with $200 \mu \mathrm{M}$ IPTG (for pJBGT3RX) and

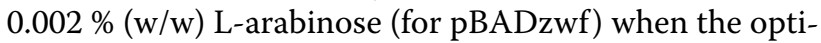
cal density at $600 \mathrm{~nm}\left(\mathrm{OD}_{600}\right)$ reached 0.2 . Cultivations were performed aerobically and the dissolved oxygen was maintained above $30 \%$ by manually increasing airflow and stirring speed. Antifoam was added as required.

\section{Analysis of cultivation samples}

The $\mathrm{OD}_{600}$ was monitored in a spectrophotometer (Genesys 20, Thermo scientific) after dilution to an $\mathrm{OD}_{600}$ of approximately 0.1 in saline solution $(0.9 \%$, w/v NaCl). $\mathrm{CDW}$ was determined, in triplicate, by taking $5 \mathrm{ml} \mathrm{sam}$ ples into pre-weighed dry glass tubes, which were centrifuged at $2000 \mathrm{~g}$ for $5 \mathrm{~min}$, followed by re-suspension of the pellet in $5 \mathrm{ml}$ saline solution and a second centrifugation at $2000 \mathrm{~g}$ for $5 \mathrm{~min}$. The resulting cell pellets were dried over night at $105{ }^{\circ} \mathrm{C}$ and weighed the next morning. The supernatant of the CDW sample was filtered (VWR collection, $0.45 \mu \mathrm{m}$ ) and stored at $-20{ }^{\circ} \mathrm{C}$ until analysis.
These samples were used to measure the concentration of $3 \mathrm{HB}$ and HAc, using the enzymatic kits Megazyme D-3-hydroxybutyrate Assay (Cat No. K-DBHA) and Boehringer Mannheim (Cat No.10148261035) respectively. To determine the concentration of glucose, glutamate and nitrogen, samples of $2 \mathrm{ml}$ cell culture were rapidly taken into pre-weighed tubes containing $2 \mathrm{ml}$ of cold $0.13 \mathrm{M}$ perchloric acid and then centrifuged at $2000 \mathrm{~g}$ for $10 \mathrm{~min} .3 .5 \mathrm{ml}$ of the supernatant was neutralized with $75 \mu \mathrm{L}$ of cold $\mathrm{K}_{2} \mathrm{CO}_{3}\left(500 \mathrm{~g} \mathrm{~L}^{-1}\right)$ and put on ice for $15 \mathrm{~min}$ to allow precipitation of salts. The sample was centrifuged again at $2000 \mathrm{~g}$ for $5 \mathrm{~min}$. Supernatants for analysis of glucose and ammonia were filtered (VWR collection, $0.45 \mu \mathrm{m}$ ) and stored at $-20{ }^{\circ} \mathrm{C}$ until analysis. Ammonia and glucose concentrations were determined with the enzymatic kits Megazyme ammonia assay kit rapid (Cat No. K-AMIAR) and Boehringer Mannheim (Cat No. 10716251035) respectively. Glutamate concentrations were determined with BioProfile Flex Analyzer, Nova Biomedical. SDS-PAGE and western blot were performed as described previously [22] to confirm the presence of the enzymes coded for by the $r x$ and $z w f$ genes.

\section{Purification of recombinant acetoacetyl-CoA reductase}

To study the cofactor dependence of $r x$, a glycerol stock stored at $-80{ }^{\circ} \mathrm{C}$ of E. coli AF1000 pTrc99RX, containing $r x$ with a His-tag, was inoculated to $500 \mathrm{ml} \mathrm{mini-}$ mal medium in a $5 \mathrm{~L}$ baffled shake flask. The cells were induced at OD 0.2 with $200 \mu \mathrm{M}$ IPTG and cultivated at $37^{\circ} \mathrm{C}$ and $180 \mathrm{rpm}$. At approximately OD 3, the cell culture was centrifuged and re-suspended in IMAC washing buffer $(20 \mathrm{mM}$ sodium phosphate, $0.5 \mathrm{M} \mathrm{NaCl}$, $10 \mathrm{mM}$ imidazole, $\mathrm{pH} 7.4$ ) at $4{ }^{\circ} \mathrm{C}$. For each gram of wet cell weight, $10 \mathrm{ml}$ of buffer was added. The temperature was maintained at $4{ }^{\circ} \mathrm{C}$ throughout the purification. The cells were disrupted by French Press (French Pressure cell press, SLM Instruments) at 800 bar. The cell debris was then removed by centrifugation at $10.000 \mathrm{~g}$ for $60 \mathrm{~min}$. The enzyme was purified on a $5 \mathrm{ml}$ HiTrap IMAC FF column charged with $\mathrm{Ni}^{2+}$ (GE Healthcare Life Sciences) according to the manufacturers instructions. The column was equilibrated with 10 column volumes of binding buffer $(20 \mathrm{mM}$ sodium phosphate, $0.5 \mathrm{M} \mathrm{NaCl}, 20 \mathrm{mM}$ imidazole) at a flow of $5 \mathrm{ml} \mathrm{min}{ }^{-1}$. The sample was thereafter loaded at $1 \mathrm{ml} \mathrm{min}{ }^{-1}$. The column was washed with binding buffer at $5 \mathrm{ml} \mathrm{min}{ }^{-1}$ until the absorbance at $280 \mathrm{~nm}$ reached a steady base-line. A step elution $(20 \mathrm{mM}$ sodium phosphate, $0.5 \mathrm{M} \mathrm{NaCl}, 500 \mathrm{mM}$ imidazole) was done and a single fraction was collected. The eluted fraction was buffer changed to $125 \mathrm{mM}$ Tris- $\mathrm{HCl}$ on a PD10 desalting column (GE Healthcare Life Sciences) according to the manufacturers instructions. The enzyme concentration was determined spectrophotometrically at 
$280 \mathrm{~nm}$. Finally, kinetic analysis was performed immediately after the concentration determination.

\section{Kinetic characterization of the acetoacetyl-CoA reductase} The activity of the acetoacetyl-CoA reductase was assayed spectrophotometrically (Cary 50 Bio UV visible) at $340 \mathrm{~nm}$ and $25^{\circ} \mathrm{C}$. All reactions were performed with $100 \mu \mathrm{l}$ enzyme solution and $20 \mu \mathrm{M}$ of acetoacetyl-CoA. The final volume was $1 \mathrm{ml}$ and $125 \mathrm{mM}$ Tris- $\mathrm{HCl}(\mathrm{pH}$ 8.0) was used as a buffer. The indicated concentrations (Fig. 2) of NADPH or NADH were used [23].

\section{Evolutionary and primary sequence analyses of acetoacetyl-CoA reductase}

In order to study the cofactor dependence of the acetoacetyl-CoA reductase $(r x)$ from $H$. boliviensis, its phylogenetic relatedness to enzymes with known specificity was studied. Protein sequences for acetoacetyl-CoA reductases from H. boliviensis, Zoogloea ramigera, Allochromatium vinosum, Azotobacter vinelandii and Cupriavidus necator were aligned using the Muscle program included in the MEGA 6 software package. To improve the bootstrap values between groups, sequences with high homology to the original enzymes were also included in the alignment. Phylogenetic relationship among enzymes was found by maximum-likelihood (ML) tree-building strategy, and was evaluated using the bootstrap method with 1000 bootstrap replications. The phylogenetic tree for reductases was constructed using a WAG with frequencies $(+F)$ model, with uniform mutation rates among amino acid sites and complete deletion of gaps and missing data.

\section{Additional file}

Additional file 1: Figure S1. Genetic map of pJBGT3RX. Table S1. Comparison of (R)-3-hydroxybutyrate production with and without tes $B$ overexpression.

\begin{abstract}
Abbreviations
3HB: (R)-3-hydroxybutyrate; PHB: poly (3-hydroxybutyrate); HAc: acetic acid; 3HB-COA: (R)-3-hydroxybutyrate-CoA; PPP: pentose phosphate pathway; OD: optical density; CDW: cell dry weight; Glc: glucose; Glu: glutamate; IPTG:


to cell dry weight; $q_{\text {HAc }}$ : specific production rate of acetic acid; $q_{3 H B}$ : specific production rate of $(R)$-3-hydroxybutyrate; $r_{3 н \mathrm{~B}}$ : volumetric $(R)$-3-hydroxybutyrate production rate; $\mathrm{K}_{\mathrm{M}}$ : saturation constant; $\mathrm{k}_{\text {cat }}$ : rate constant; $\mathrm{V}_{\text {max }}$ : maximum rate; DOT: dissolved oxygen tension; IMAC: immobilized metal affinity chromatography; PCR: polymerase chain reaction; SLIC: sequence and ligation independent cloning; SDS-PAGE: sodium dodecyl sulfate polyacrylamide gel; ML: maximum-likelihood; +F: frequencies.
\end{abstract}

\section{Authors' contributions}

MPZ performed the majority of the experimental work. GS contributed to the experimental work. MPZ and GS wrote the manuscript. MGM contributed to the experimental work and revised the manuscript. JJ contributed to the experimental work and the manuscript. MG contributed to the experimental work and revised the manuscript. JQ and GL were responsible for the original concept, supervised the work and contributed to the manuscript. All authors have read and approved the final manuscript.

\section{Author details}

${ }^{1}$ Division of Industrial Biotechnology, School of Biotechnology, KTH Royal Institute of Technology, AlbaNova University Center, SE 10691 Stockholm, Sweden. ${ }^{2}$ Center of Biotechnology, Faculty of Science and Technology, Universidad Mayor de San Simón, Cochabamba, Bolivia.

\section{Acknowledgements}

The Swedish Research Council Formas and The Swedish International Development Agency SIDA are acknowledged for their financial support.

\section{Availability of data and materials}

The constructed plasmid pJBGT3Rx carrying genes from $\mathrm{H}$. boliviensis is available at the School of Biotechnology, Division of Industrial Biotechnology, KTH Royal Institute of Technology, AlbaNova University Center, Stockholm-Sweden, on the charge of Prof. Gen Larsson.

The sequences of acetoacetyl-CoA reductases used in the phylogenetic tree can be found with their respective access numbers at NCBI.

\section{Competing interests}

The authors declare that they have no competing interests.

\section{Funding}

The Swedish Research Council Formas and The Swedish International Development Agency SIDA supported this work.

Received: 11 March 2016 Accepted: 20 May 2016

Published online: 01 June 2016

\section{References}

1. Shin J, Kim H, Kim D, Lee SY. Production of bulk chemicals via novel metabolic pathways in microorganisms. Biotechnol Adv. 2013:31:925-35.

2. Madison LL, Huisman GW. Metabolic engineering of Poly(3-Hydroxyalkanoates): from DNA to Plastic. Microbiol Mol Biol Rev. 1999;63:21-53.

3. Suzuki M, Suzuki M, Sato K, Dohi S, Sato T, Matsuura A, Hiraide A. Effect of beta-hydroxybutyrate, a cerebral function improving agent, on cerebral hypoxia, anoxia and ischemia in mice and rats. Jpn J Pharmacol. 2001;87:143-50.

4. Kashiwaya Y, Takeshima T, Mori N, Nakashima K, Clarke K, Veech RL. D- $\beta$-Hydroxybutyrate protects neurons in models of Alzheimer's and Parkinson's disease. Proc Natl Acad Sci USA. 1999;97:5440-4.

5. Seebach D, Chow HF, Jackson RFW, Sutter MA, Thaisrivongs S, Zimmermann J. (+)-11,11'-Di-O-methylelaiophylidene-preparation from elaiophylin and total synthesis from (R)-3-Hydroxybutyrate and (S)-Malate. Liebigs Ann Chem. 1986; 509:1281-308.

6. Lee SY, Lee Y. Metabolic engineering of Escherichia coli for production of enantiomerically pure (R)-(-)-hydroxycarboxylic acids. Appl Environ Microbiol. 2003;69:3421-6.

7. Quillaguamán J, Doan-Van T, Guzmán H, Guzmán D, Martín J, Everest A, Hatti-Kaul R. Poly(3-hydroxybutyrate) production by Halomonas boliviensis in fed-batch culture. Appl Microbiol Biotechnol. 2008;78:227-32.

8. Guzmán D, Balderrama-Subieta A, Cardona-Ortuño C, Guevara-Martínez M, Callisaya-Quispe N, Quillaguamán J. Evolutionary patterns of carbohydrate transport and metabolism in Halomonas boliviensis as derived from its genome sequence: influences on polyester production. Aquatic Biosystems. 2012;8:9.

9. Peoples OP, Sinskey AJ. Poly-beta-hydroxybutyrate biosynthesis in Alcaligenes eutrophus H16. Characterization of the genes encoding beta-ketothiolase and acetoacetyl-CoA reductase. J Biol Chem. 1989;264:15293-7.

10. Liu Q, Ouyang S, Chung A, Wu Q, Chen GQ. Microbial production of R-3-hydroxybutiryc acid by recombinant E. coli harboring genes of phbA, phbB and tesB. Appl Microbiol Biotechnol. 2007;76:811-8.

11. Fukui T, Ito M, Saito T, Tomita K. Purification and characterization of NADP-linked acetoacetyl-CoA reductase from Zoogloea ramigera I-16-M. Biochim Biophys Acta. 1987:917:365-71. 
12. Liebergesell M, Steinbuchel A. Cloning and nucleotide sequences of genes relevant for biosynthesis of poly(3-hydroxybutyric acid) in Chromatium vinosum strain D. Eur J Biochem. 1992;209:135-50.

13. Lim SJ, Jung YM, Shin HD, Lee YH. Amplification of the NADPH-related genes zwf and gnd for the oddball biosynthesis of PHB in an E. coli transformant harboring a cloned phbCAB operon. J Biosci Bioeng. 2002;93:543-9.

14. Vemuri GN, Altman E, Sangurdekar DP, Khodursky AB, Eiteman MA. Overflow metabolism in Escherichia coli during steady-state growth: transcriptional regulation and effect of the redox ratio. Appl Environ Microb. 2006:72:3653-61.

15. Guevara-Martínez M, Sjöberg K, Sjöberg G, Jarmander J, Perez-Zabaleta M, Quillaguamán J, Larsson G. Regulating the production of (R)-3-hydroxybutyrate in Escherichia coli by $\mathrm{N}$ or P limitation. Front Microbiol. 2015;6:844.

16. Jarmander J, Belotserkovsky J, Sjöberg G, Guevara-Martínez M, PerezZabaleta M, Quillaguamán J, Larsson G. Cultivation strategies for production of (R)-3-hydroxybutyric acid from simultaneous consumption of glucose, xylose and arabinose by Escherichia coli. Microb Cell Fact. 2015;14:51.

17. Gao HJ, Wu Q, Chen GQ. Enhanced production of D-(-)-3-hydroxybutyric acid by recombinant Escherichia coli. FEMS Microbiol Lett. 2002;213:59-65.
18. Sandén AM, Prytz I, Tubulekas I, Förberg C, Le H, Hektor A, Neubauer P, Pragai Z, Harwood C, Ward A, et al. Limiting factors in Escherichia coli fed-batch production of recombinant proteins. Biotechnol Bioeng. 2003;81:158-66.

19. Jeong JY, Yim HS, Ryu JY, Lee HS, Lee JH, Seen DS, Kang SG. One-step sequence- and ligation-independent cloning as a rapid and versatile cloning method for functional genomics studies. Appl Environ Microb. 2012;78:5440-3.

20. Li MZ, Elledge SJ. SLIC: a Method for Sequence- and Ligation-Independent Cloning. Method Mol Biol. 2012;852:158-66.

21. Amann E, Ochs B, Abel KJ. Tightly regulated tac promoter vectors useful for the expression of unfused and fused proteins in Escherichia coli. Gene. 1988;69:301-15.

22. Jarmander J, Gustavsson M, Thi-Huyen D, Samuelson P, Larsson G. A dual tag system for facilitated detection of surface expressed proteins in Escherichia coli. Microb Cell Fact. 2012;11:118-28.

23. Satoh Y, Minamoto N, Tajima K, Munekata M. Polyhydroxyalkanoate synthase from Bacillus sp. INTO05 is composed of phaC and phaR. J Biosci Bioeng. 2002;94:343-50.

\section{Submit your next manuscript to BioMed Central and we will help you at every step:}

- We accept pre-submission inquiries

- Our selector tool helps you to find the most relevant journal

- We provide round the clock customer support

- Convenient online submission

- Thorough peer review

- Inclusion in PubMed and all major indexing services

- Maximum visibility for your research

Submit your manuscript at www.biomedcentral com/submit 